\title{
Expression of CD163 and HLA-DR molecules on the monocytes in chronic lymphocytic leukemia patients
}

\author{
Wioleta Kowalska
}

Chair and Department of Clinical Immunology, Medical University of Lublin, Lublin, Poland

\begin{abstract}
Introduction. Human peripheral blood monocytes are the part of the leukemia microenvironment. We examined three monocyte subgroups: classical $\left(\mathrm{CD} 14^{++} \mathrm{CD} 16^{-}\right)$, intermediate $\left(\mathrm{CD} 14^{++} \mathrm{CD} 16^{+}\right)$and non-classical $\left(\mathrm{CD} 14^{+} \mathrm{CD} 16^{++}\right)$monocytes. As these subpopulations can be also characterized by different levels of HLA-DR and CD163, we evaluated their expression on monocyte subpopulations of patients with chronic lymphocytic leukemia (CLL) and healthy individuals.

Material and methods. The monocyte subsets in peripheral blood of CLL patients $(n=40)$ and healthy controls $(\mathrm{n}=10)$ were evaluated by flow cytometry. The monoclonal antibodies: anti-CD14 FITC, anti-CD16 PE-Cy5, anti-CD163 PE, anti-HLA-DR PE were used.

Results. The percentage of CD16-positive monocytes was significantly higher in CLL patients than in healthy donors. The highest percentage of $\mathrm{CD} 163^{+}$monocytes is in the 'classical' $\left(\mathrm{CD} 14^{++} \mathrm{CD} 16^{-}\right)$population. In turn, the non-classical monocytes constituted the majority of cells lacking HLA-DR expression. In CLL patients, there was no statistically significant relationship between the percentage of each monocyte subpopulation and the stage according to Rai Staging of CLL.

Conclusions. The presence of CD163 on classical monocytes suggests that these cells have anti-inflammatory properties. Besides, the low expression of HLA-DR on non-classical monocytes may result in impaired ability to stimulate the immune system. (Folia Histochemica et Cytobiologica 2020, Vol. 58, No. 1, 17-24)
\end{abstract}

Key words: monocyte; subpopulations; CD163; HLA-DR; chronic lymphocytic leukemia

\section{Introduction}

Chronic lymphocytic leukemia (CLL) patients suffer from the immunological dysfunctions that refer not only to B cells, but also to other elements of the immune system, including T cells, NK cells, neutrophils and monocytes/macrophages [1]. The observed inhibition of antitumor response during CLL may be ascribed to cells that form the tumor microenvironment, which favor the clonal expansion of B lymphocytes and promote their survival [2]. Monocytes are mononuclear cells involved in the innate immune responses. In CLL they could have a significant influence on the regulation of the growth

Correspondence address: Wioleta Kowalska, $\mathrm{PhD}$

Chair and Department of Clinical Immunology,

Medical University of Lublin,

Chodzki 4a, Lublin 20-093, Poland

email:w.kowalska.lub@gmail.com or elimination of cancer cells [3]. Based on differences in the expression of surface markers CD14 (receptor for lipopolysaccharide, i.e. LPS, LPS-R) and CD16 (Fc $\gamma$ RIII receptor), three subpopulations of monocytes can be identified: the classical $\left(\mathrm{CD} 14^{++} \mathrm{CD} 16^{-}\right)$, the intermediate $\left(\mathrm{CD} 14^{++} \mathrm{CD} 16^{+}\right)$and the non-classical $\left(\mathrm{CD} 14^{+} \mathrm{CD} 16^{++}\right)$monocytes [4-6]. Under physiological conditions, the percentage of classical monocytes constitutes about $95 \%$ of all monocytes circulating in the peripheral blood. The role of the remaining $5 \%$ of $\mathrm{CD} 16^{+}$monocytes has not been clearly defined [7].

The disproportion between the percentage of CD16 ${ }^{-}$and $\mathrm{CD} 16^{+}$monocytes was observed in cancer patients [8]. It is believed that these abnormalities may have a significant impact on the proangiogenic and anti-tumor capacities of $\mathrm{CD} 16^{+}$monocytes [9]. A higher expression of HLA-DR and CD86 molecules was observed on classical monocytes (CD16-negative) [10]. On the other hand, among CD16-positive mono- 
cytes, the intermediate monocytes $\left(\mathrm{CD} 14^{++} \mathrm{CD} 16^{+}\right)$ have a high expression of the CD163 [11]. It is currently believed that the CD163 protein is involved in the uptake of the hemoglobin-haptoglobin complex and the regulation of inflammatory processes $[12,13]$. CD163 may also be in a soluble form (soluble CD163, sCD163) [14]. The role of the sCD163 molecule has not been exactly explained. However, it seems to be involved not only in the removal of hemoglobin-haptoglobin complexes but also in the anti-inflammatory response [13]. Its higher level was found in hematological cancers, including chronic lymphocytic leukemia [15]. Moreover, CD163 is certainly a marker of macrophage activity and is generally thought to be associated with downregulation of inflammation, but its biological role still has not been fully elucidated $[14,15]$. Monocytes are one of the least known immune cells with a potentially important role in the pathogenesis of CLL.

The aim of our study was to evaluate the expression of CD163 and HLA-DR molecules on the monocyte subpopulations in CLL patients and healthy individuals.

\section{Materials and methods}

Characteristics of the study group. The study group consisted of 40 patients with newly diagnosed CLL at the Department of Hematooncology and Bone Marrow Transplantation of the Medical University of Lublin, Poland. The diagnosis of CLL was based on the clear recommendations developed by the International Workshop on Chronic Lymphocytic Leukemia (iwCLL) [16].

The age of patients ranged from 39 to 82 years (median: 63 ys). The study group included 24 men and 16 women. According to the Rai classification [17], patients were divided into 3 groups: the low risk group (stage 0$)-22$ patients, intermediate-risk group (stage I/II) - 11 patients, high-risk group (stage III/IV) -7 patients. Detailed characteristics of the examined group of CLL patients are presented in Table 1. The control group consisted of 10 healthy volunteers ( 7 men, 3 women). Age of donors ranged from 24 to 54 years (median: $47 \mathrm{ys}$ ).

This study was approved by the Bioethics Committee of the Medical University of Lublin (No. KE-0254/49/2016). All patients gave their written consent to participate in the research.

Blood collection and preparation of samples for flow cytometry. Approximately $5 \mathrm{ml}$ of venous blood was collected into an EDTA-coated tube from each patient and healthy person. The material for the study was immediately processed. Subpopulations of monocytes circulating in the peripheral blood of CLL patients and healthy controls were
Table 1. Characteristics of chronic lymphocytic leukemia (CLL) patients

\begin{tabular}{|c|c|}
\hline $\begin{array}{l}\text { The criteria for } \\
\text { differentiating patients }\end{array}$ & Number of patients \\
\hline $\begin{array}{l}\text { Sex } \\
\text { Female }(\%) \\
\text { Male }(\%)\end{array}$ & $\begin{array}{l}16(40 \%) \\
24(60 \%)\end{array}$ \\
\hline $\begin{array}{l}\text { Rai stage } \\
0 \\
\text { I/II } \\
\text { III/IV }\end{array}$ & $\begin{array}{c}22(55 \%) \\
11(27.5 \%) \\
7(17.5 \%)\end{array}$ \\
\hline $\begin{array}{l}\text { ZAP-70 (cut-off point 20\%) } \\
\text { ZAP-70-positive } \\
\text { ZAP-70-negative }\end{array}$ & $\begin{array}{l}17(42.5 \%) \\
23(57.5 \%)\end{array}$ \\
\hline $\begin{array}{l}\text { CD38 (cut-off point } \mathbf{3 0 \%} \text { ) } \\
\text { CD38-positive } \\
\text { CD38-negative }\end{array}$ & $\begin{array}{l}11(27.5 \%) \\
29(72.5 \%)\end{array}$ \\
\hline & Median value (minimum-maximum) \\
\hline Age at diagnosis (years) & $63(39-82)$ \\
\hline WBC [G/l)] & $25.2(10.1-112.5)$ \\
\hline LYM [G/l] & $18.8(5.5-106.3)$ \\
\hline$\beta_{2} \mathrm{M}[\mathrm{mg} / \mathrm{dl}]$ & $2.4(1.36-5.39)$ \\
\hline LDH [IU/l] & $373(266-619)$ \\
\hline $\mathrm{HGB}[\mathrm{g} / \mathrm{dl}]$ & $14.00(8.1-17.2)$ \\
\hline $\mathrm{CD} 19^{+} \mathrm{CD}^{+}{ }^{+} \mathrm{ZAP}-70^{+}(\%)$ & $13.41(0.2-44.3)$ \\
\hline $\mathrm{CD} 19^{+} \mathrm{CD}^{+} \mathrm{CD}_{3} 8^{+}(\%)$ & $8.43(0.3-80.9)$ \\
\hline $\mathrm{CD} 19^{+} \mathrm{CD}^{+}(\%)$ & $3.23(0.9-16.6)$ \\
\hline
\end{tabular}

Abbreviations: WBC - white blood cell count; LYM - absolute lymphocyte count; $\mathrm{LDH}$ - lactate dehydrogenase; $\beta 2 \mathrm{M}-\beta 2$-microglobulin; HGB - hemoglobin

determined by flow cytometry. Monocyte cell surface antigen assessments were performed with the following monoclonal antibodies conjugated with fluorochromes: anti-CD14 FITC (BD Pharmingen); anti-CD16 PE-Cy5 (BD Pharmingen); anti-HLA-DR PE (BioLegend); anti-CD163 PE (BioLegend). $100 \mu \mathrm{l}$ of blood was taken into vials and labeled with monoclonal antibodies.

Samples were incubated for 20 minutes at room temperature. The next step was RBC lysis with FACS Lysis Solution (Becton Dickinson) for 10 minutes at room temperature. Right after centrifugation at $700 \times \mathrm{g}$ for 5 minutes, supernatant was poured out and the marked cells were rinsed twice with phosphate buffered saline PBS $(700 \times \mathrm{g})$.

A BD FACSCalibur ${ }^{\mathrm{TM}}$ flow cytometer (BD Biosciences, Franklin Lakes, NJ, USA) with CellQuestPro software (BD Biosciences) were used for cytometric analysis and data evaluation.

Statistical analysis. The statistical analysis was carried out with GraphPad Prism 5.0. software (GraphPad Software, 
Inc. La Jolla, California, USA). U Mann-Whitney test or Wilcoxon test were used. Median, minimal and maximal values and IQR were used for data description. The Spearman rank correlation coefficient was used in correlation tests. The level of significance was set at $\mathrm{p}<0.05$.

\section{Results}

The percentage of classical monocytes in patients with CLL was significantly lower in relation to the control group $(\mathrm{p}<0.0001)$, while the percentage of $\mathrm{CD} 14^{++} \mathrm{CD} 16^{+}$and $\mathrm{CD} 14^{+} \mathrm{CD} 16^{++}$monocytes was significantly higher compared to the control group ( $\mathrm{p}<0.01)$ (Fig. 1, Table 2). The percentage of $\mathrm{CD} 14^{++} \mathrm{CD} 16-$ classical monocytes (median: $75.56 \%$ ) was significantly higher than CD16-positive monocytes in CLL patients. The latter group includes the CD $14{ }^{++} \mathrm{CD} 16{ }^{+}$intermediate subset (median: $6.34 \%$ ) and non-classical CD14 ${ }^{+} \mathrm{CD} 16^{++}$(median: $10.65 \%$ ) subpopulation $(\mathrm{p}<0.01)$ (Fig. 2, Table 2$)$.

Of all subpopulations, classical monocytes accounted for the highest percentage of $\mathrm{CD}_{163}{ }^{+}$monocytes (median: $96.73 \%$ ), while non-classical monocytes presented the lowest percentage of $\mathrm{CD} 163^{+}$cells (median: 5.12\%) (Fig. 3, Table 3).

The non-classical CD $14{ }^{+} \mathrm{CD} 16^{++} \mathrm{HLA}-\mathrm{DR}{ }^{+}$ monocytes had the lowest percentage of HLA-DR ${ }^{+}$ cells (median: $73.36 \%$ ) compared to classical HLA$\mathrm{DR}^{+}$(median: $97.73 \%$ ) and intermediate HLA-DR ${ }^{+}$ cells (median: $96.77 \%)(\mathrm{p}<0.0001)$ (Fig. 4, Table 4).

In addition, the study showed that the percentage of subpopulations of classical, intermediate and non-classical monocytes expressing CD163 does not correlate with leukocytosis, lymphocytosis and serum $\beta 2$ microglobulin concentration ( $\mathrm{p}>0.05$ ). The percentage of CD14 ${ }^{++} \mathrm{CD} 16^{-} \mathrm{CD} 163^{+}$monocytes showed a negative correlation with the concentration of $\mathrm{CD}^{+}$ $\mathrm{CD} 19^{+}$leukemia cells $(\mathrm{r}=-0.51 ; \mathrm{p}<0.05)$. According to the results, the percentage of CD14+HLA-DR ${ }^{\text {low/neg }}$ monocytes showed a negative correlation only with the percentage of $\mathrm{CD} 14^{++} \mathrm{CD} 16^{-} \mathrm{CD} 163^{+}$monocytes

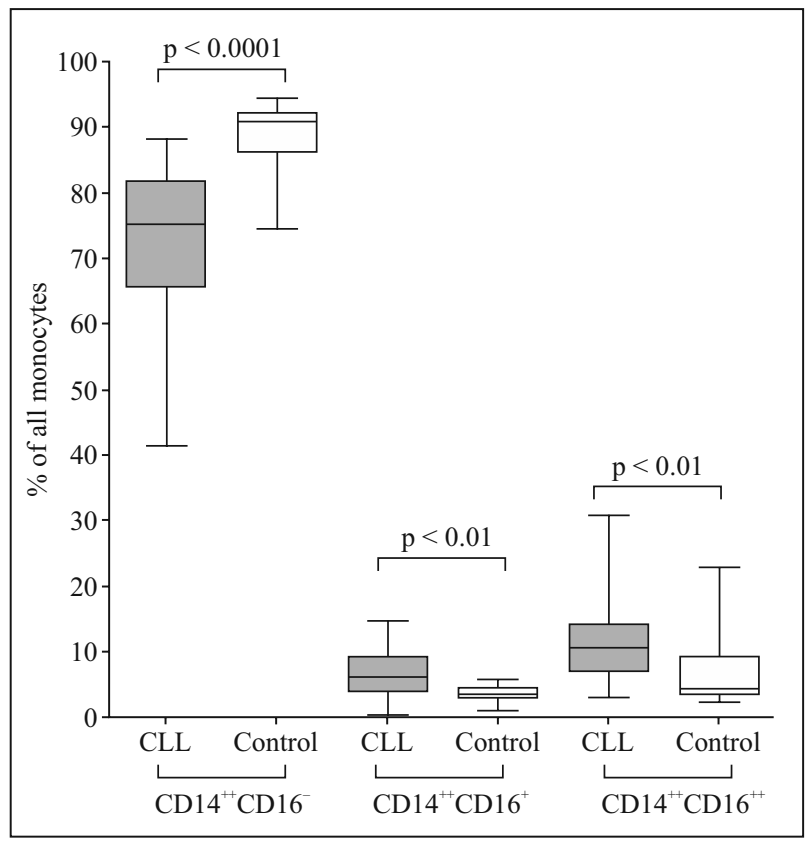

Figure 1. Comparison of the percentage of individual monocyte subpopulations: classical $\left(\mathrm{CD} 14^{++} \mathrm{CD} 16^{-}\right)$, intermediate $\left(\mathrm{CD} 14^{++} \mathrm{CD} 16^{+}\right)$and non-classical $\left(\mathrm{CD} 14^{+} \mathrm{CD} 16^{++}\right)$among all monocytes in CLL patients and healthy volunteers studied by flow cytometry as described in Methods. $P$ values were calculated using the non-parametric U Mann-Whitney test. Bars, line and whiskers represent median, maximum, minimum and IQR, respectively. Abbreviations: CLL — chronic lymphocytic leukemia; IQR — interquartile range.

among all subpopulations of monocytes $(\mathrm{r}=-0.55$; $\mathrm{p}<0.05)$.

\section{Discussion}

Among the populations of immune cells, monocytes are one of the least known cells with potentially important role in the pathogenesis of CLL [18]. Since monocytes appear to play an important role in the pathogenesis of CLL, the present study presents the

Table 2. Statistical analysis of the percentage of monocytes with the phenotypes CD $14^{++} \mathrm{CD} 16^{-}, \mathrm{CD} 14^{++} \mathrm{CD} 16^{+}$and $\mathrm{CD} 14^{+} \mathrm{CD} 16^{++}$in CLL patients and in the control group

\begin{tabular}{|l|c|c|c|c|c|c|}
\hline \multirow{2}{*}{ Variables } & \multicolumn{2}{|c|}{$\mathbf{C D 1 4}^{++} \mathbf{C D 1 6}^{-}(\boldsymbol{\%})$} & \multicolumn{2}{c|}{$\mathbf{C D 1 4}^{++} \mathbf{C D 1 6}^{+}(\boldsymbol{\%})$} & \multicolumn{2}{c|}{ CD14 $^{+} \mathbf{C D 1 6}^{++}\left(\boldsymbol{\%}_{)}\right.$} \\
\cline { 2 - 7 } & $\mathbf{C L L}$ & Control & CLL & Control & CLL & Control \\
\hline Median & 75.56 & 91.01 & 6.34 & 3.17 & 10.65 & 4.55 \\
\hline Min & 41.42 & 74.66 & 0.24 & 1.14 & 3.03 & 2.25 \\
\hline Max & 88.35 & 94.54 & 14.58 & 5.68 & 30.70 & 22.75 \\
\hline IQR & 16.29 & 6.18 & 5.54 & 1.78 & 7.59 & 5.89 \\
\hline
\end{tabular}

Abbreviations: CLL — chronic lymphocytic leukemia; MIN — minimum; MAX — maximum; IQR — interquartile range 


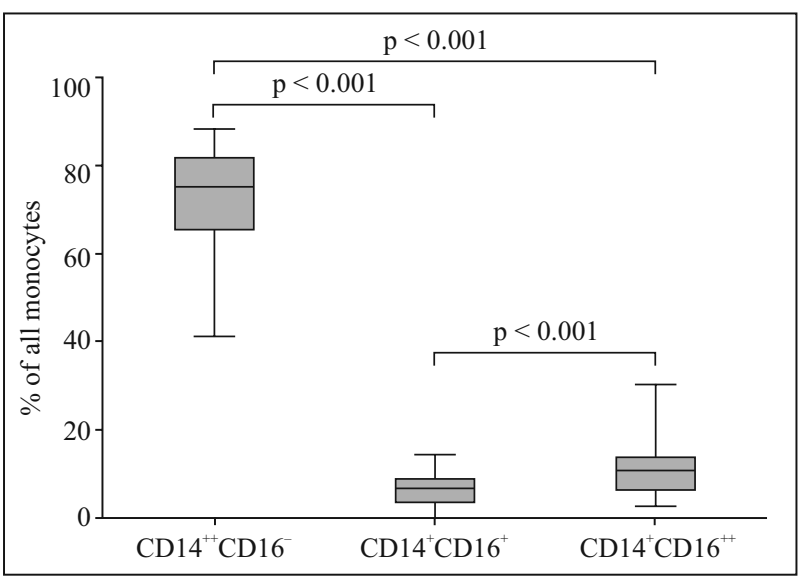

Figure 2. Comparison of the percentage of individual monocyte subpopulations among all monocytes in CLL patients was performed as described in the Legend to Figure 1. $P$ values were calculated using the non-parametric Wilcoxon test. Bars, other graphical symbols and abbreviations as in the description of Figure 1.

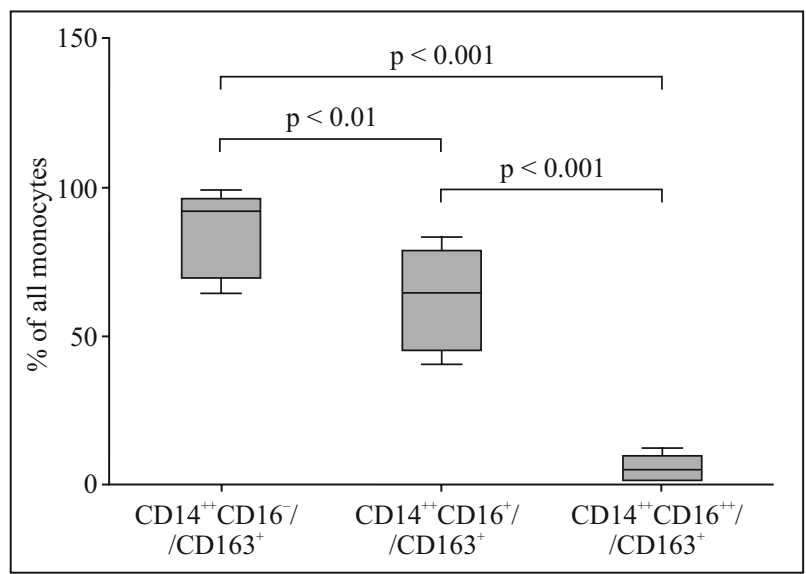

Figure 3. Comparison of the percentage of monocyte subpopulations expressing CD163 in CLL patients was performed as described in the Legend to Figure 1. $P$ values were calculated using the non-parametric Wilcoxon test. Bars, other graphical symbols and abbreviations as in the description of Figure 1.

Table 3. Statistical analysis of the percentage of monocytes with the phenotypes CD $14^{++} \mathrm{CD} 16^{-}, \mathrm{CD} 14^{++} \mathrm{CD} 16^{+}$and $\mathrm{CD} 14^{+} \mathrm{CD} 16^{++}$expressing the CD163 molecule in the studied group of CLL patients

\begin{tabular}{|l|c|c|c|}
\hline Variables & $\mathbf{C D 1 4}^{++} \mathbf{C D 1 6}-\mathbf{C D 1 6 3}^{+}(\boldsymbol{\%})$ & $\mathbf{C D 1 4}^{++} \mathbf{C D 1 6}^{+} / \mathbf{C D 1 6 3}^{+} \mathbf{( \% )}$ & $\mathbf{C D 1 4}^{+} \mathbf{C D 1 6}^{++} / \mathbf{C D 1 6 3}^{+} \mathbf{( \% )}^{-1}$ \\
\hline Median & 96.73 & 63.70 & 5.12 \\
\hline Min & 62.10 & 44.87 & 0.30 \\
\hline Max & 100.0 & 78.64 & 12.99 \\
\hline IQR & 26.88 & 29.98 & 9.13 \\
\hline
\end{tabular}

Abbreviations as in the description of Table 2.

evaluation of the proportion of the monocytes subpopulation in CLL Although the discovery of three different subpopulations of monocytes suggests the existence of the functional differences between these cells their properties are still not fully understood. Monocytes analyzed in CLL patients were divided into classical monocytes $\left(\mathrm{CD} 14^{++} \mathrm{CD} 16^{-}\right)$and monocytes expressing CD16 molecules, which are differentiated into two subpopulations: the intermediate monocytes $\mathrm{CD} 14^{++} \mathrm{CD} 16^{+}$and the non-classical monocytes $\mathrm{CD} 14^{+} \mathrm{CD} 16^{++}[6]$.

It is assumed that the increased expression of CD16 on the surface of monocytes may correlate with their activation process [8]. An increase in the percentage of CD16-positive monocytes observed in the present study may indicate that CLL lymphocytes stimulate $\mathrm{CD}_{16}{ }^{+}$monocytes and lead to their activation. This is in line with Maffei et al. [19], who concluded that the increase in the percentage of non-classical monocytes may result from their stimulation by leukemic lymphocytes. According to the latter study, the $\mathrm{CD} 14^{+} \mathrm{CD} 16^{++}$

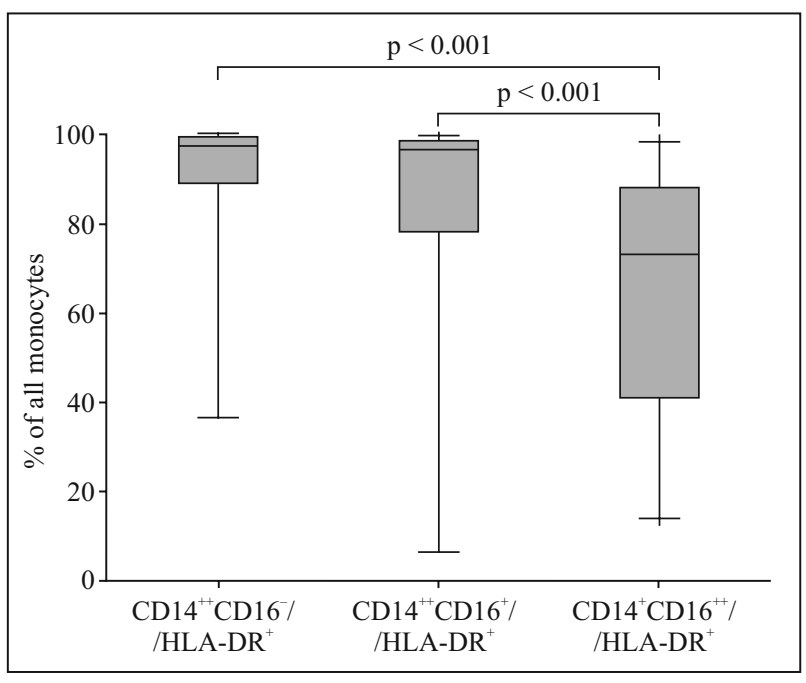

Figure 4. Evaluation of the percentage of individual HLADR positive monocyte subsets in patients with CLL was performed as described in the Legend to Figure 1. $P$ values were calculated using the non-parametric Wilcoxon test. Bars, other graphical symbols, and abbreviations as in the description of Figure 1. 
Table 4. Comparison of the percentage of classical, intermediate and non-classical monocytes with HLA-DR expression in CLL patients

\begin{tabular}{|c|c|c|c|}
\hline Variables & $\mathrm{CD14}^{++} \mathrm{CD16}^{-} / \mathrm{HLA}^{-D R^{+}}(\%)$ & $\mathrm{CD}^{++}{ }^{++} \mathrm{CD}^{+}{ }^{+} / \mathrm{HLA}^{-D R^{+}}(\%)$ & $\mathrm{CD}^{+}{ }^{+} \mathrm{CD} 6^{++} / \mathrm{HLA}^{-D R^{+}}(\%)$ \\
\hline MEDIAN & 97.73 & 96.77 & 73.36 \\
\hline MIN & 36.47 & 6.270 & 14.38 \\
\hline MAX & 100.0 & 100.0 & 100.0 \\
\hline IQR & 10.22 & 20.45 & 47.37 \\
\hline
\end{tabular}

Abbreviations as in the description of Table 2.

monocytes do not produce cytokines in response to LPS and are unable to phagocytose [19].

In this study we observed that patients with CLL possess a higher percentage of non-classical monocytes $\mathrm{CD} 14^{+} \mathrm{CD} 16^{++}$and a significantly higher percentage of intermediate monocytes $\mathrm{CD} 14^{++} \mathrm{CD} 16^{+}$ as compared to the healthy group. Italiani et al. [5] also showed a similar percentage of monocytes circulating in the peripheral blood of CLL patients, classical monocytes $(85 \%)$, intermediates $(5 \%)$ and non-classical (10\%) [5].

It is worth mentioning that the increase in the percentage of monocytes expressing CD16 was also observed in other pathological conditions, e.g. during bacterial, viral or parasitic infections [20] and in acute or chronic conditions such as sepsis or atherosclerosis [8], chronic liver disease [21], rheumatoid arthritis [22], and renal diseases [23, 24].

The role of monocytes expressing CD16 during the mobilization of the immune system is not fully understood. One theory explains the differentiation of monocytes by the process of maturation and differentiation of these cells into the peripheral blood macrophages [8]. The differences in the percentage of each subpopulation of monocytes observed in CLL patients, compared to the proportion observed in healthy subjects may be due to the fact that classical monocytes may differentiate into tissue macrophages TAMs (Tumor Associated Macrophages) [25, 26].

The differences relate to, among others, the degree of expression of HLA-DR, CD86 and CD1d, which determine their ability to present antigens [8]. Furthermore, the $\mathrm{CD} 14^{++} \mathrm{CD} 16^{+}$intermediate monocytes have a high expression of CD163 molecule [14] that inhibits activation and proliferation of T cells [27]. It is also a specific marker of monocytes/macrophages exhibiting strong anti-inflammatory properties [28]. Recent studies have shown that anti-inflammatory monocytes $\mathrm{CD} 14^{++} \mathrm{CD} 16^{+}$are also associated with significant expression of TGF- $\beta$. This cytokine enables them to inhibit T-dependent response, and to stimulate proliferation of $\mathrm{T}$ regulatory cells [1].
Of all subpopulations, classical monocytes accounted for the highest percentage of CD163+ monocytes, while non-classical monocytes had the lowest percentage of $\mathrm{CD}_{163}{ }^{+}$cells. Moniuszko et al. [9] also observed high expression of the CD163 molecule on classical monocytes. The percentage of $\mathrm{CD} 14^{++} \mathrm{CD} 16^{+} \mathrm{CD} 163^{+}$monocytes was higher than the percentage of non-classical CD163 ${ }^{+}$monocytes. It is believed that the presence of CD163 on the surface of monocytes affects the ability of these cells to inhibit the inflammatory response [8] as the CD163+ monocytes may have anti-inflammatory properties [29]. Therefore, it is assumed that due to the disturbed antigen presentation process and abnormal maturation of dendritic cells, the activity of the immune system in patients with CLL decreases [6, 19]. Moreover, monocytes have reduced ability to stimulate the immune system, due to impaired antigen presentation to T cells [30]. Furthermore, the researchers suggest that a subpopulation of monocytes characterized by increased percentage of CD163-positive cells present in inflamed or tumor tissues can polarize to macrophages M2, in particular subtype M2d called TAM [31-33]. It is worth recalling that the presence of macrophages with the expression of CD163 in the tumor microenvironment in patients with breast cancer is unfavorable prognostic factor. Results of a recent Polish study suggest the positive correlation between the presence of CD163 macrophage and tumor size [34]. Perhaps the classical or intermediate CD163-positive monocytes differentiate into TAMs. Our studies also assessed the expression of HLA-DR on monocytes in CLL patients. The analysis showed that the percentage of cells expressing HLA-DR among classical monocytes $\left(\mathrm{CD} 14^{++} \mathrm{CD} 16^{-}\right)$is significantly higher compared with the percentage of non-classical CD $14^{+} \mathrm{CD} 16^{++} \mathrm{HLA}-\mathrm{DR}^{+}$. Additionally, the percentage of $\mathrm{CD} 14^{++} \mathrm{CD} 16^{+} \mathrm{HLA}-\mathrm{DR}{ }^{+}$monocytes among intermediate monocytes was significantly higher than the percentage of $\mathrm{CD} 14^{+} \mathrm{CD} 16^{++}$ HLA-DR ${ }^{+}$. The majority of non-classical monocytes exhibit only low expression of HLA-DR (HLA-DR ${ }^{- \text {low }}$ ). 


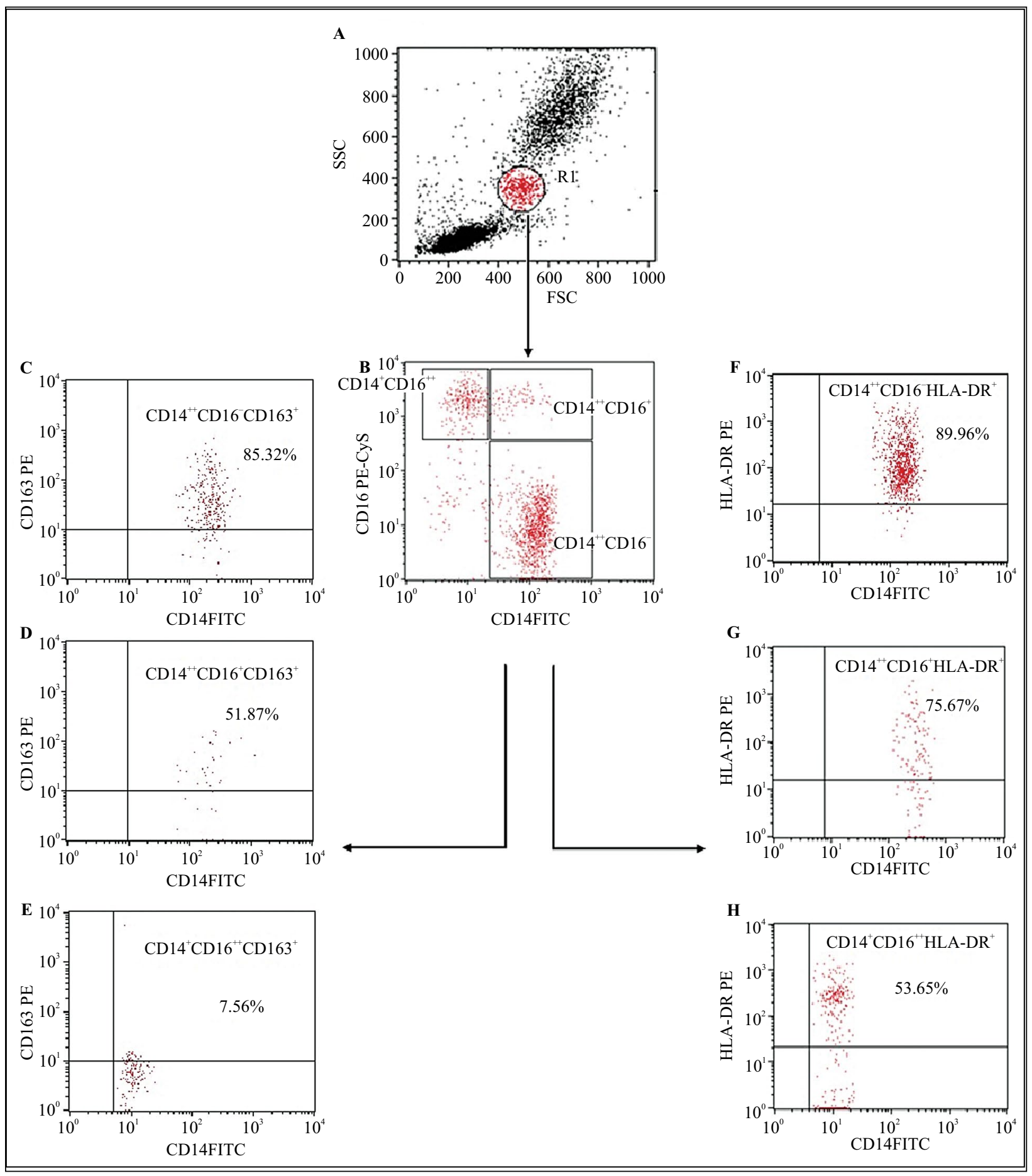

Figure 5. The dot plots of representative data from one chronic lymphocytic leukemia patient illustrate the analysis method for the identification of monocyte subpopulations in peripheral blood following three-color staining. (A) Monocyte population was gated (Region R1) using FSC and SSC plot. (B) Next, the monocytes accumulated in the R1 were analyzed for staining of monocyte subpopulations. We used dot plots of CD14 FITC versus CD16 PE-Cy5. The dot plot shows classical $\left(\mathrm{CD} 14^{++} \mathrm{CD} 16-\right)$, intermediate $\left(\mathrm{CD} 14^{++} \mathrm{CD} 16^{+}\right)$and non-classical $\left(\mathrm{CD} 14^{+} \mathrm{CD} 16^{++}\right)$monocytes. Expression of $\mathrm{CD} 163(\mathbf{C}$, D, E) and HLA-DR (F, G, H) was assessed in each of these subpopulations. Abbreviations: FSC — forward scatter; SSC - side scatter.

It suggests that these cells have a reduced ability to stimulate the immune system, due to disturbed presentation of antigens to $T$ cells [30]. The increased number of CD14 ${ }^{+}$HLA-DR ${ }^{\text {lowneg }}$ cells in the peripheral blood is present in many cancers and is related to the stage, grade, gender and tumor size [35]. Gustafson 
et al. [10] observed an increased percentage of HLA$\mathrm{DR}^{\text {low }}$ monocytes in patients with CLL compared to the control group $(18.6 \% \pm 11.5 \%$ vs. $9.9 \% \pm 6.4 \%)$. The CD14+ HLA-DR ${ }^{\text {low/neg }}$ monocytes secrete large amounts of IL- 10 and TGF- $\beta$ that stimulate regulatory T cells (Treg) proliferation and cause an alteration in the maturation of dendritic cells [10]. Moreover, an increased percentage of monocytes with low HLA-DR expression was noted in patients with acute hepatic failure, which may result in higher susceptibility to infection due to the significantly reduced immune function [21]. Monocytes exhibiting high expression of CD163 and low expression of HLA-DR may be described as a subpopulation with anti-inflammatory properties and the ability to inhibit the anti-tumor response [30, 36].

\section{Conclusions}

A statistically significant increase in the percentage of intermediate and non-classical monocytes was found in CLL patients in comparison to the control group. The highest percentage of CD163+ cells was observed in "classical" monocytes. The presence of this receptor suggests that these cells have anti-inflammatory properties. In addition, in CLL patients the highest percentage of HLA-DR ${ }^{\text {neg/low }}$ cells expression was observed among non-classical monocytes, which means that these cells have probably impaired ability to stimulate the immune system.

\section{Acknowledgements}

The work was financed from the Young Researcher grant MNmb 519 obtained from subsidies for the development of young scientists and participants of doctoral studies at the Medical University of Lublin. The study was performed using the equipment purchased under the Project "The equipment of innovative laboratories doing research on new medicines used in the therapy of civilization and neoplastic diseases" within the Operational Program Development of Eastern Poland 2007-2013, Priority Axis I Modern Economy, Operations I.3 Innovation Promotion.

\section{References}

1. Caligaris-Cappio F. Inflammation, the microenvironment and chronic lymphocytic leukemia. Haematologica. 2011; 96(3): 353-355, doi: 10.3324/haematol.2010.039446, indexed in Pubmed: 21357715.

2. Choi MY, Kashyap MK, Kumar D. The chronic lymphocytic leukemia microenvironment: Beyond the B-cell receptor. Best Pract Res Clin Haematol. 2016; 29(1): 40-53, doi: 10.1016/j. beha.2016.08.007, indexed in Pubmed: 27742071.

3. Ab Kadir R, Zainal Ariffin SH, Megat Abdul Wahab R, et al. Characterization of mononucleated human peripheral blood cells. ScientificWorldJournal. 2012; 2012: 843843, doi: 10.1100/2012/843843, indexed in Pubmed: 22666162.

4. Ziegler-Heitbrock L. Blood monocytes and their subsets: established features and open questions. Front Immunol. 2015; 6: 423, doi: 10.3389/fimmu.2015.00423, indexed in Pubmed: 26347746.

5. Italiani P, Boraschi D. From Monocytes to M1/M2 Macrophages: Phenotypical vs. Functional Differentiation. Front Immunol. 2014; 5: 514, doi: 10.3389/fimmu.2014.00514, indexed in Pubmed: 25368618.

6. Ziegler-Heitbrock L, Ancuta P, Crowe S, et al. Nomenclature of monocytes and dendritic cells in blood. Blood. 2010; 116(16): e74-e80, doi: 10.1182/blood-2010-02-258558, indexed in Pubmed: 20628149.

7. Kzhyshkowska J, Gudima A, Moganti K, et al. Perspectives for monocyte/macrophage-based diagnostics of chronic inflammation. Transfus Med Hemother. 2016; 43(2): 66-77, doi: 10.1159/000444943, indexed in Pubmed: 27226789.

8. Łapuć I, Eljaszewicz A, Kłoczko J, et al. Rola monocytów w patogenezie przewlekłej białaczki limfocytowej. Acta Haematologica Polonica. 2014; 45(4): 340-346, doi: 10.1016/j. achaem.2014.06.001.

9. Moniuszko M, Bodzenta-Lukaszyk A, Kowal K, et al. Enhanced frequencies of CD14++CD16+, but not CD14+CD16+, peripheral blood monocytes in severe asthmatic patients. Clin Immunol. 2009; 130(3): 338-346, doi: 10.1016/j.clim.2008.09.011, indexed in Pubmed: 18952503.

10. Gustafson MP, Abraham RS, Lin Yi, et al. Association of an increased frequency of CD14+ HLA-DR lo/neg monocytes with decreased time to progression in chronic lymphocytic leukaemia (CLL). Br J Haematol. 2012; 156(5): 674-676, doi: 10.1111/j.1365-2141.2011.08902.x, indexed in Pubmed: 22050346.

11. Buechler C, Ritter M, Orsó E, et al. Regulation of scavenger receptor CD163 expression in human monocytes and macrophages by pro- and antiinflammatory stimuli. J Leukoc Biol. 2000; 67(1): 97-103, indexed in Pubmed: 10648003.

12. Onofre G, Kolácková M, Jankovicová K, et al. Scavenger receptor CD163 and its biological functions. Acta Medica (Hradec Kralove). 2009; 52(2): 57-61, indexed in Pubmed: 19777868.

13. Moestrup SK, M ller HJ. CD163: a regulated hemoglobin scavenger receptor with a role in the anti-inflammatory response. Ann Med. 2004; 36(5): 347-354, doi: 10.1080/07853890410033171, indexed in Pubmed: 15478309.

14. Lapuc I, Bolkun L, Eljaszewicz A, et al. Circulating classical CD14++CD16- monocytes predict shorter time to initial treatment in chronic lymphocytic leukemia patients: Differential effects of immune chemotherapy on monocyte-related membrane and soluble forms of CD163. Oncol Rep. 2015; 34(3): 1269-1278, doi: 10.3892/or.2015.4088, indexed in Pubmed: 26135617.

15. Nederby L, Roug AS, Knudsen SS, et al. Soluble CD163 as a prognostic biomarker in B-cell chronic lymphocytic leukemia. Leuk Lymphoma. 2015; 56(11): 3219-3221, doi: 10.3109/10428194.2015.1026899, indexed in Pubmed: 25747973.

16. Hallek M. Chronic lymphocytic leukemia: 2017 update on diagnosis, risk stratification, and treatment. Am J Hematol. 2017; 92(9): 946-965, doi: 10.1002/ajh.24826, indexed in $\mathrm{Pu}-$ bmed: 28782884 .

17. Rai KR. A critical analysis of staging in CLL. In: Gale RP, Rai KR, ed.Chronic Lymphocytic Leukemia: Recent Progress and Future Directions. New York: Alan R. Liss; 1987:253-264. 
18. Herishanu Y, Katz BZ, Lipsky A, et al. Biology of chronic lymphocytic leukemia in different microenvironments: clinical and therapeutic implications. Hematol Oncol Clin North Am. 2013; 27(2): 173-206, doi: 10.1016/j.hoc.2013.01.002, indexed in Pubmed: 23561469.

19. Maffei R, Bulgarelli J, Fiorcari S, et al. The monocytic population in chronic lymphocytic leukemia shows altered composition and deregulation of genes involved in phagocytosis and inflammation. Haematologica. 2013; 98(7): 1115-1123, doi: 10.3324/haematol.2012.073080, indexed in Pubmed: 23349302.

20. Tolouei Semnani R, Moore V, Bennuru S, et al. Human monocyte subsets at homeostasis and their perturbation in numbers and function in filarial infection. Infect Immun. 2014; 82(11): 4438-4446, doi: 10.1128/IAI.01973-14, indexed in Pubmed: 25114121.

21. Abeles RD, McPhail MJ, Sowter D, et al. CD14, CD16 and HLA-DR reliably identifies human monocytes and their subsets in the context of pathologically reduced HLA-DR expression by CD14(hi) /CD16(neg) monocytes: Expansion of CD14(hi) /CD16(pos) and contraction of CD14(lo) /CD16(pos) monocytes in acute liver failure. Cytometry A. 2012; 81(10): 823-834, doi: 10.1002/cyto.a.22104, indexed in Pubmed: 22837127.

22. Luo Q, Xiao P, Li X, et al. Overexpression of CD64 on CD14CD16 and CD14CD16 monocytes of rheumatoid arthritis patients correlates with disease activity. Exp Ther Med. 2018; 16(3): 2703-2711, doi: 10.3892/etm.2018.6452, indexed in $\mathrm{Pu}-$ bmed: 30210612.

23. Schepers E, Houthuys E, Dhondt A, et al. Transcriptome analysis in patients with chronic kidney disease on hemodialysis disclosing a key role for CD16+CX3CR1+ monocytes. PLoS One. 2015; 10(4): e0121750, doi: 10.1371/journal. pone.0121750, indexed in Pubmed: 25830914.

24. Stansfield BK, Ingram DA. Clinical significance of monocyte heterogeneity. Clin Transl Med. 2015; 4: 5, doi: 10.1186/ s40169-014-0040-3, indexed in Pubmed: 25852821.

25. Chen YCE, Mapp S, Blumenthal A, et al. The duality of macrophage function in chronic lymphocytic leukaemia. Biochim Biophys Acta Rev Cancer. 2017; 1868(1): 176-182, doi: 10.1016/j.bbcan.2017.03.006, indexed in Pubmed: 28347751.

26. Galletti G, Caligaris-Cappio F, Bertilaccio MTS. B cells and macrophages pursue a common path toward the development and progression of chronic lymphocytic leukemia. Leukemia. 2016; 30(12): 2293-2301, doi: 10.1038/leu.2016.261, indexed in Pubmed: 27677742.

27. Tsukamoto M, Seta N, Yoshimoto K, et al. CD14CD16+ intermediate monocytes are induced by interleukin-10 and positively correlate with disease activity in rheumatoid arthritis. Arthritis Res Ther. 2017; 19(1): 28, doi: 10.1186/s13075016-1216-6, indexed in Pubmed: 28183329.

28. Mandl M, Schmitz S, Weber C, et al. Characterization of the CD14+ +CD16+ monocyte population in human bone marrow. PLoS One. 2014; 9(11): e112140, doi: 10.1371/journal. pone.0112140, indexed in Pubmed: 25369328.

29. Yang H, Wang H, Levine YA, et al. Identification of CD163 as an antiinflammatory receptor for HMGB1-haptoglobin complexes. JCI Insight. 2016; 1(7), doi: 10.1172/jci.insight.85375, indexed in Pubmed: 27294203.

30. Liu J, Zhou Y, Huang Q, et al. CD14HLA-DR expression: A novel prognostic factor in chronic lymphocytic leukemia. Oncol Lett. 2015; 9(3): 1167-1172, doi: 10.3892/ol.2014.2808, indexed in Pubmed: 25663875.

31. Allavena P, Mantovani A. Immunology in the clinic review series; focus on cancer: tumour-associated macrophages: undisputed stars of the inflammatory tumour microenvironment. Clin Exp Immunol. 2012; 167(2): 195-205, doi: 10.1111/j.13652249.2011.04515.x, indexed in Pubmed: 22235995.

32. Derlindati E, Dei Cas A, Montanini B, et al. Transcriptomic analysis of human polarized macrophages: more than one role of alternative activation? PLoS One. 2015; 10(3): e0119751, doi: 10.1371/journal.pone.0119751, indexed in $\mathrm{Pu}-$ bmed: 25799240.

33. Zarif JC, Hernandez JR, Verdone JE, et al. A phased strategy to differentiate human CD14+monocytes into classically and alternatively activated macrophages and dendritic cells. Biotechniques. 2016; 61(1): 33-41, doi: 10.2144/000114435, indexed in Pubmed: 27401672.

34. Medrek C, Pontén F, Jirström K, et al. The presence of tumor associated macrophages in tumor stroma as a prognostic marker for breast cancer patients. BMC Cancer. 2012; 12: 306, doi: 10.1186/1471-2407-12-306, indexed in Pubmed: 22824040

35. Yuan XK, Zhao XK, Xia YC, et al. Increased circulating immunosuppressive CD14(+)HLA-DR(-/low) cells correlate with clinical cancer stage and pathological grade in patients with bladder carcinoma. J Int Med Res. 2011; 39(4): 1381-1391, doi: 10.1177/147323001103900424, indexed in Pubmed: 21986138.

36. Mazumdar R, Evans P, Culpin R, et al. The automated monocyte count is independently predictive of overall survival from diagnosis in chronic lymphocytic leukaemia and of survival following first-line chemotherapy. Leuk Res. 2013; 37(6): 614-618, doi: 10.1016/j.leukres.2013.02.020, indexed in $\mathrm{Pu}-$ bmed: 23522450 .

Submitted: 26 October, 2019

Accepted after reviews: 21 February, 2020 Available as AoP: 16 March, 2020 